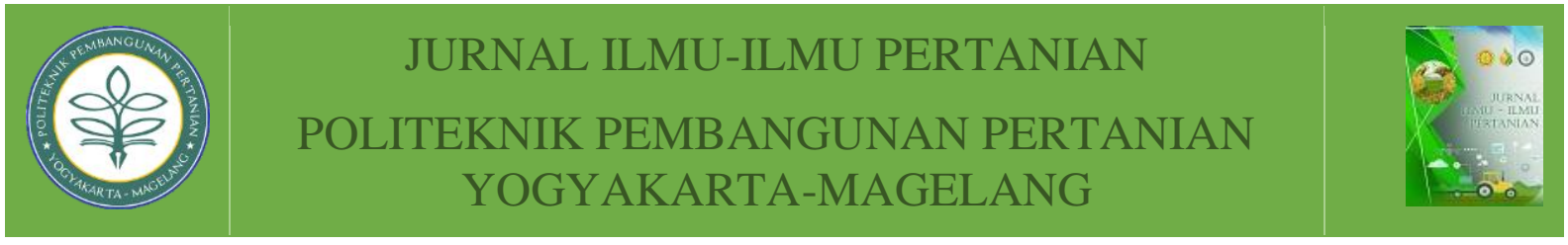

\title{
STRATEGI PENGEMBANGAN PASAR LELANG CABAI (Studi Kasus Pasar Lelang Cabai di Kabupaten Sleman D.I Yogyakarta)
}

\author{
Shelva Aprilia ${ }^{1}$, Gunawan Yulianto ${ }^{2}$, RR. Siti Astuti ${ }^{3}$ \\ ${ }^{1}$ Politeknik Pembangunan Pertanian Yogyakarta Magelang, Yogyakarta, 55167 \\ ${ }^{2}$ Politeknik Pembangunan Pertanian Yogyakarta Magelang, Yogyakarta, 55167 \\ ${ }^{3}$ Politeknik Pembangunan Pertanian Yogyakarta Magelang, Yogyakarta, 55167
}

Received
Accepted
Published
Copyright Notice
cc) (7) 8

: February $22^{\text {nd }}, 2021$

: February $22^{\text {nd }}, 2021$

: June $9^{\text {th }}, 2021$

: Authors retain copyright and grant the journal right of first publication with This work is licensed under a Creative Commons Attribution-Non Commercial 4.0 International License.

\begin{abstract}
ABSTRAK: Kajian ini bertujuan untuk merumuskan faktor internal dan eksternal Pasar Lelang Cabai Kabupaten Sleman serta merumuskan strategi yang diterapkan dalam pengembangan Pasar Lelang Cabai Kabupaten Sleman. Kajian ini menggunakan metode deskriptif kualitatif, dilaksanakan bulan Februari s.d Juni 2020 di Pasar Lelang Cabai Kabupaten Sleman, Daerah Istimewa Yogyakarta. Data yang digunakan adalah data sekunder dan data primer dengan metode pengumpulan data secara triangulasi meliputi wawancara mendalam, observasi partisipatif, dan dokumentasi. Penentuan informan kajian secara purposive sampling. Analisis data menggunakan analisis SWOT. Analisa kajian meliputi faktor-faktor utama lingkungan internal dan eksternal, diidentifikasi dengan matriks IFAS dan EFAS. Hasil dari matriks IFAS dan EFAS digunakan untuk dasar penyusunan strategi alternatif dengan matriks SWOT dan matriks IE. Tahap terakhir yaitu pengambilan keputusan dari alternatif strategi yang ada menggunakan QSPM yang menghasilkan prioritas strategi. Prioritas strategi yang dapat direkomendasikan untuk diterapkan terlebih dahulu oleh Pasar Lelang Cabai Kabupaten Sleman adalah mempertahankan dan meningkatkan kualitas dan kuantitas cabai di pasar lelang untuk menjamin kepuasan pedagang dengan memanfaatkan teknologi dan dukungan dari Dinas Pertanian Pangan dan Perikanan Kabupaten Sleman.
\end{abstract}

Kata Kunci : Strategi Pengembangan, SWOT, Pasar Lelang Cabai.

ABSTRACT: This study aimed to understand the internal and external factors in the Chili Auction Market in Sleman regency and formulate a strategy that is applied to the development of The Chili Auction Market in Sleman Regency. This study used a qualitative descriptive method. The study was conducted in February-Juni 2020 in the Chili Auction Market. The data used were secondary and primary data by the data collection methods, in-depth interviews, participatory observation, and documentation. The sampling uses the purposive sampling. The

**shelvaapr@gmail.com ${ }^{1}$ 
data analysis using the SWOT analysis. The results of the study were analyzed by the IFAS dan EFAS matrix. The results of the matrix were used for the basis of the alternative strategy planning with SWOT matrix and IE matrix. The final step was determining the priority strategy by using QSPM analysis. This strategy, which was recommended to be implemented by the Chili Auction Market in Sleman Regency, improves quantity and quality in Auction Market to ensure merchant satisfaction by using technology and support from the Department of Agriculture, Food and Fisheries Sleman Regency.

Keywords: Development Strategy, SWOT, Chili Auction Market.

\section{PENDAHULUAN}

Berbagai kendala dihadapi dalam agribisnis cabai diantaranya adalah belum ada keseimbangan antara produksi dengan serapan pasar, yang mengakibatkan harga berfluktuasi dan pemasaran umumnya dilakukan oleh tengkulak dengan harga yang seringkali merugikan petani (Swastika, 2017). Suryowati (2016) menyatakan bahwa diantara beberapa komoditas pangan strategis, pada tahun 2016 cabai merah merupakan komoditas yang memiliki pola distribusi paling panjang, akibatnya perbedaan harga dari produsen ke konsumen adalah yang paling besar diantara komoditas lain. Survei pola distribusi komoditas strategis 2018 oleh Badan Pusat Statistik menunjukan bahwa persentase Margin Perdagangan dan Pengangkutan (MPP) komoditas cabai merah adalah 47,10 persen. Hal tersebut berarti bahwa kenaikan harga cabai merah dari tingkat petani sampai ke konsumen akhir sebesar 47,10 persen. Diantara 8 komoditas strategis, Margin Perdagangan dan Pengangkutan (MPP) cabai merah masih menempati urutan kedua terbesar setelah bawang merah dengan persentase 49,06 persen. Oleh karena itu dibutuhkan inovasi untuk memutus rantai pasok cabai merah di Indonesia.

Keberadaan pasar lelang adalah salah satu upaya untuk memutus rantai pasok yang dapat memperkuat harga ditingkat petani dan menstabilkan harga ditingkat konsumen. Menurut Badan Pengawas Perdagangan Berjangka Komoditi (2017) pasar lelang komoditas merupakan pasar terorganisir dan wahana bertemunya para pembeli dan penjual dengan menggunakan sistem lelang. Berdirinya pasar lelang komoditas bertujuan untuk efisiensi mata rantai perdagangan, sarana pembentukan harga yang transparan, menciptakan harga referensi serta membangun dan memperluas jaringan usaha.

Dinas Pertanian dan Ketahanan Pangan Daerah Istimewa Yogyakarta menetapkan komoditas hortikultura unggulan salah satunya adalah cabai besar. Selain itu tujuan Pemerintah Daerah Istimewa Yogyakarta bidang pertanian pada Laporan Keuangan Pertanggungjawaban Gubernur Daerah Istimewa Yogyakarta (LKPJ) tahun 2019 adalah meningkatkan kelembagaan sektor pertanian yang perlu didukung dengan sistem jejaring pemasaran yang tepat (PEMDA DIY, 2019).

Kabupaten Sleman merupakan salah satu penyangga produksi cabai nasional. Setiap hari antara 3-8 ton cabai dikirim ke Pasar Induk Jakarta maupun Pasar Induk Sumatera. Kabupaten Sleman merupakan penghasil cabai terbesar kedua setelah Kabupaten Kulon Progo di Daerah Istimewa Yogyakarta. Pada tahun 2018 produksi cabai di Kabupaten Sleman sebesar 138.453 kuintal dari total produksi cabai di Daerah Istimewa Yogyakarta sebesar 445.901 kuintal.

Tanaman sayuran di Kabupaten Sleman yang memiliki potensi dan produksi relatif besar pada tahun 2018 antara lain cabai merah sebanyak 71.706 kuintal, cabai rawit sebanyak 66.747 kuintal, sawi sebanyak 14.740 kuintal dan 
kangkung sebanyak 14.255 kuintal (Dinas Pertanian Pangan dan Perikanan Kab Sleman, 2018).

Pasar Lelang Cabai di Kabupaten Sleman Daerah Istimewa Yogyakarta berada di bawah Perkumpulan Petani Hortikultura Puncak Merapi yang sebelumnya bernama Asosiasi Petani Hortikultura Puncak Merapi. Perkumpulan Petani Hortikultura Puncak Merapi berdiri pada tahun 2017 dan telah berbadan hukum tahun 2020 yang menjadi induk petani hortikultura di Kabupaten Sleman, dibentuk atas dasar kesamaan kepentingan petani yaitu untuk menyatukan harga cabai di Kabupaten Sleman serta meningkatkan daya tawar petani cabai terutama pada saat pasokan cabai sedang melimpah.

Pasar Lelang Cabai Kabupaten Sleman dikelola oleh 12 orang yang terdiri dari Koordinator, Pengelola Pemasaran, Administrasi, Sortasi, Penimbangan, dan Pengemasan. Sejak berdirinya Pasar Lelang Cabai Kabupaten Sleman dianggap telah mampu memutus rantai pemasaran yang panjang dan dapat merugikan petani. Cabai yang terkumpul dari petani dijual dengan sistem lelang tertutup. Pembeli yang menang adalah calon pembeli yang menawar dengan harga tertinggi. Menurut Pengelola Pasar Lelang Cabai selisih harga cabai antara menjual ke pasar lelang dengan pemasaran lain mencapai Rp. 2.000 $4.000 / \mathrm{kg}$.

Tahun 2018 Pasar Lelang Cabai Kabupaten Sleman menerima pasokan cabai merah sebanyak 2.522,39 kuintal dari total 71.706 kuintal produksi cabai merah di Kabupaten Sleman atau baru menerima pasokan cabai merah di Sleman sebesar 3,5\% sedangkan untuk cabai rawit pada tahun 2018 Pasar Lelang Cabai Kabupaten Sleman menerima pasokan sebanyak 1.684,08 kuintal dari total 66.747 kuintal produksi cabai rawit di Kabupaten Sleman atau baru menerima pasokan cabai rawit di Sleman sebesar 2,5\% (Dinas Pertanian Pangan dan Perikanan Kabupaten
Sleman,2018). Rendahnya pasokan cabai merah dan cabai rawit yang masuk ke Pasar Lelang diduga karena masih banyaknya petani yang menjual hasil panen cabainya ke tengkulak. Selain itu berdasarkan permasalahan yang ditemukan dilapangan, terdapat produk yang dijual petani ke Pasar Lelang belum sesuai dengan grade yang diinginkan pasar lelang sehingga proses sortasi dan grading di pasar lelang memerlukan waktu yang lama terutama saat pasokan cabai ke pasar lelang sedang melimpah.

Seiring dengan potensi cabai di Kabupaten Sleman serta untuk menjamin harga cabai ditingkat petani, meningkatkan daya tawar petani cabai jika pasokan sedang melimpah, dan menyatukan harga cabai di Kabupaten Sleman maka dirasa perlu dilakukannya upaya pengembangan Pasar Lelang Cabai Kabupaten Sleman melalui kajian Strategi Pengembangan Pasar Lelang Cabai Kabupaten Sleman, guna meningkatkan pendapatan petani yang pada akhirnya akan berdampak pada peningkatan kesejahteraan petani cabai di Kabupaten Sleman Daerah Istimewa Yogyakarta. Kajian ini dilakukan dengan tujuan untuk mengidentifikasi faktor internal dan faktor eksternal serta merumuskan strategi pengembangan Pasar Lelang Cabai di Kabupaten Sleman.

\section{METODE}

Kajian ini dilaksanakan pada Februari - Juni 2020, di wilayah Kabupaten Sleman, Daerah Istimewa Yogyakarta yang ditentukan secara purposive. Kajian ini merupakan kajian deskriptif dengan pendekatan kualitatif, jenis penelitian ini adalah studi kasus. Penentuan Pasar Lelang Cabai Kabupaten Sleman dilakukan secara Purposive dengan pertimbangan Kabupaten Sleman merupakan penghasil cabai terbesar kedua setelah Kabupaten Kulon Progo dan memiliki pasar lelang komoditas yang aktif di Daerah Istimewa Yogyakarta. 
Pengambilan sampel/informan secara purposive sebanyak 25 orang informan, Informan kunci terdiri dari 5 orang yang mengetahui dan memiliki berbagai informasi pokok yang diperlukan dalam kajian ini terdiri dari Ketua PPHPM, Sekretaris I PPHPM, Koordinator Pasar Lelang, Pemasaran dan Ketua Titik Kumpul Tempel. Informan tambahan terdiri dari 7 orang yang terlibat langsung dalam interaksi sosial yang diteliti terdiri dari Pengurus Titik Kumpul Cabai Kabupaten Sleman, Penyuluh Pertanian di Kabupaten Sleman, Pedagang (peserta lelang), dan Petugas Dinas Pertanian Pangan dan Perikanan Kabupaten Sleman. Informan tambahan terdiri dari 12 orang yang dapat memberikan informasi walaupun tidak langsung terlibat dalam interaksi sosial yang dikaji terdiri dari petani yang selalu menjual hasil panennya ke pasar lelang, petani yang tidak pernah menjual hasil panennya ke pasar lelang dan petani yang kadang-kadang menjual hasil panennya ke pasar lelang.

Data yang digunakan pada kajian ini adalah data sekunder dan data primer, data primer diperoleh dengan menggunakan gabungan teknik pengumpulan data triangulasi dengan cara :1) Wawancara (Indepth Interview) dilakukan dengan informan kunci (key informan) untuk penggalian faktor internal berupa kekuatan dan kelemahan, sedangkan wawancara dengan informan utama dan informan tambahan untuk penggalian faktor eksternal berupa peluang dan ancaman yang mempengaruhi pengembangan Pasar Lelang Cabai Kabupaten Sleman. 2) Dokumentasi merupakan catatan peristiwa yang sudah berlalu. Dokumen diambil dari informan kunci (key informan) yaitu berasal dari pengelola pasar lelang. Dokumen yang dikumpulkan berbentuk tulisan atau gambar berupa catatan harian pasar lelang, peraturan dan kebijakan. 3) Observasi Partisipatif dilakukan dengan terlibat dalam kegiatan di Pasar Lelang Cabai Kabupaten Sleman. Informasi yang digali dari observasi partisipatif yang dilakukan adalah kegiatan pengelolaan pasar lelang, kegiatan titik kumpul, interaksi yang terjadi di Pasar Lelang Cabai Kabupaten Sleman, serta kegiatan petani cabai di lahan pertaniannya.

Data sekunder dapat diperoleh dari studi literatur yang berhubungan dengan topik kajian seperti jurnal, skripsi/karya tulis atau pun data lainnya yang berhubungan dengan Pasar Lelang Cabai Kabupaten Sleman, Dinas Pertanian Pangan dan Perikanan Kabupaten Sleman, Badan Pusat Statistik (BPS), serta informasi yang berkaitan lainnya yang dapat diperoleh melalui daring. Data yang telah diperoleh disusun dan dianalisis dengan analisis SWOT, yang menjelaskan tentang kekuatan, kelemahan, peluang dan ancaman yang ditemui dalam proses wawancara, observasi partisipatif serta dokumentasi yang dilakukan kepada informan.

Menurut Rangkuti (2016) tahapan analisa SWOT adalah sebagai berikut: 1) Tahap pengumpulan data menggunakan dua matriks yaitu Matrik Faktor Strategi Eksternal (EFAS) berisi analisis faktorfaktor strategis eksternal berupa peluang dan ancaman sedangkan Matrik Faktor Strategi Internal (IFAS) berisi analisis faktor-faktor strategis internal berupa kekuatan dan kelemahan. 2) Tahap Analisis data menggunakan matrik SWOT dan matrik IE. Matrik SWOT adalah alat yang dipakai untuk menyusun faktor-faktor strategis.

Matriks ini menggambarkan secara jelas bagaimana peluang dan ancaman eksternal yang dihadapi perusahaan dapat disesuaikan dengan kekuatan dan kelemahan yang dimilikinya. Sedangkan matrik IE meliputi parameter kekuatan internal perusahaan dan pengaruh eksternal yang dihadapi perusahaan. Tujuan penggunaan model ini adalah untuk 
memperoleh strategi bisnis tingkat korporasi yang lebih detail. 3) Tahap Pengambilan Keputusan yaitu penentuan strategi yang cocok untuk digunakan dalam suatu usaha dengan menggunakan QSPM (Quantitative Strategic Planning Matrix) yaitu alat analisis yang telah disusun berdasarkan faktor internal dan eksternal.

Teknik ini digunakan untuk menentukan alternatif strategi yang paling baik. Untuk membuat matriks QSPM maka akan digunakan tahap masukan, tahap 1 dan tahap 2 yang telah dilakukan sebelumnya. Matriks QSPM ini digunakan untuk menilai secara objektif strategi yang dapat dijalankan, berdasarkan faktor kesuksesan internal dan eksternal yang telah dikenali sebelumnya (David, 2016).

Teknik analisis data juga menggunakan analisis kelayakan ekonomi untuk mengetahui seberapa jauh usaha tani yang dijalankan petani cabai di Kabupaten Sleman mampu menghasilkan keuntungan secara finansial sehingga dapat dijadikan dasar untuk memutuskan apakah usaha tersebut layak atau tidak untuk dijalankan. Analisis kelayakan ekonomi juga untuk membuktikan bahwa menjual hasil panen cabai ke pasar lelang mampu meningkatkan pendapatan petani cabai. Analisis kelayakan ekonomi budidaya cabai dapat menggunakan analisis kebutuhan modal, analisis biaya, analisis BEP, dan Benefit Cost Ratio (BCR).

\section{HASIL DAN PEMBAHASAN}

Pasar Lelang Cabai Kabupaten Sleman dibentuk berdasarkan inisiasi dari Dinas Pertanian Pangan dan Perikanan Kabupaten Sleman. Pasar Lelang Cabai Kabupaten Sleman berada dalam pengelolaan PPHPM dibentuk atas dasar kesamaan kepentingan petani yaitu untuk menyatukan harga cabai di Kabupaten Sleman dan meningkatkan daya tawar petani cabai terutama jika pasokan cabai sedang melimpah.

\section{Analisa SWOT}

\section{Identifikasi Faktor Internal}

Kekuatan Pasar Lelang Cabai Kabupaten Sleman adalah memiliki website panenin.id yang dapat digunakan sebagai pencatatan keuangan dan fungsi lainnya, pengelola lelang maupun titik kumpul menguasai teknologi informasi seperti android dan laptop, pengelola lelang maupun titik kumpul memiliki kemampuan dalam sortir dan grading cabai, PPHPM maupun pengelola lelang dan titik kumpul masuk dalam pertemuan kelompok tani untuk mempromosikan pasar lelang, sarana prasarana pasar lelang sudah cukup lengkap, dan semua petani cabai Kabupaten Sleman dapat masuk ke Pasar Lelang Cabai Kabupaten Sleman.

Kelemahan Pasar Lelang Cabai Kabupaten Sleman adalah hasil sortiran cabai tidak dimanfaatkan/dikembalikan ke petani, sortasi dan grading membutuhkan waktu yang lama terutama saat panen raya cabai di Kabupaten Sleman, terdapat perbedaan manajemen dan sistem antara Pasar Lelang Cabai Kabupaten Sleman dan titik kumpul cabai di Kabupaten Sleman, peserta lelang hanya melibatkan pedagang dari Daerah Istimewa Yogyakarta dan Jawa Tengah, dan kegiatan lelang masih menggunakan saluran telepon, SMS, whatsapp dan lainnya.

\section{Identifikasi Faktor Eksternal \\ Peluang Pasar Lelang Cabai} Kabupaten Sleman adalah pedagang memilih membeli cabai di Pasar Lelang karena kualitas cabai yang dijamin, jaringan pemasaran pedagang ke pasar lokal bahkan merambah ke luar kota dan keluar pulau jawa, tengkulak menentukan harga dengan acuan harga yang ada di pasar lelang sehingga harga cabai dapat dikontrol dan tidak terlalu jatuh, petani percaya dengan pengelola lelang dan titik kumpul, website penenin.id untuk pasar lelang, dan titik kumpul dari Bank Indonesia, adanya 
dukungan dari Dinas Pertanian Pangan dan Perikanan Kabupaten Sleman untuk pasar lelang dan titik kumpul, adanya bantuan sarana prasarana, petani yang rajin menjual hasil panennya ke pasar lelang atau titik kumpul, dan dukungan penyuluh yang mendorong kelompok tani binaannya untuk menjual hasil panen ke pasar lelang dan penyuluhan tentang pengembangan teknis budidaya cabai.

Ancaman Pasar Lelang Cabai Kabupaten Sleman adalah pedagang yang membeli cabai di tengkulak, belum tercapainya pemenuhan kebutuhan cabai di Kabupaten Sleman oleh pasar lelang, belum ada persyaratan yang spesifik untuk menjadi pedagang/konsumen di pasar lelang/titik kumpul yang berpotensi menyebabkan gagal bayar, adanya tengkulak terutama di wilayah sentra-sentra cabai di Kabupaten Sleman, serangan hama dan penyakit pada tanaman cabai petani sehingga tidak lolos sortir, terdapat petani yang tidak menyortir cabainya sebelum dibawa ke pasar lelang, proses budidaya cabai belum sesuai sehingga perlu ditingkatkan lagi baik dari analisis usaha, pelaksanaan budidaya maupun pemanfaatan teknologi.

Matriks Faktor Strategi Internal (IFAS)

Berikut ini hasil dari tahap input data berupa Matriks Faktor Strategi Internal (IFAS). Hasil analisis matriks IFAS menunjukkan total nilai skor sebesar 3,02. Total skor tersebut berada di atas rata-rata yaitu 2,5. Skor total tersebut mengindikasikan bahwa Pasar Lelang Cabai Kabupaten Sleman memiliki posisi internal yang kuat yaitu dapat merespon secara baik kekuatan dan dapat meminimalisir kelemahan.

Tabel 1. Matriks IFAS

\begin{tabular}{|c|c|c|c|c|}
\hline \multicolumn{5}{|c|}{ Faktor Strategi Internal } \\
\hline & unatan & Bobot & Rating & Skor \\
\hline A & $\begin{array}{l}\text { Pasar Lelang Cabai memiliki website panenin.id yang dapat digunakan } \\
\text { sebagai pencatatan keuangan dan fungsi lainnya. }\end{array}$ & 0,1 & 4 & 0,40 \\
\hline B & $\begin{array}{l}\text { Pengelola lelang maupun titik kumpul menguasai teknologi informasi } \\
\text { seperti android dan laptop }\end{array}$ & 0.09 & 3,4 & 0,31 \\
\hline $\mathrm{C}$ & $\begin{array}{l}\text { Pengelola lelang maupun titik kumpul memiliki kemampuan dalam sortir } \\
\text { dan grading cabai }\end{array}$ & 0,1 & 3,4 & 0,34 \\
\hline $\mathrm{D}$ & $\begin{array}{l}\text { PPHPM maupun pengelola lelang dan titik kumpul masuk dalam } \\
\text { pertemuan kelompok tani untuk mempromosikan pasar lelang }\end{array}$ & 0,08 & 3 & 0,24 \\
\hline $\mathrm{E}$ & Sarana prasarana pasar lelang sudah cukup lengkap & 0,09 & 3,4 & 0,31 \\
\hline F & $\begin{array}{l}\text { Semua petani cabai Kabupaten Sleman dapat masuk ke Pasar Lelang Cabai } \\
\text { Kabupaten Sleman }\end{array}$ & 0,1 & 2,8 & 0,28 \\
\hline \multicolumn{5}{|c|}{ Kelemahan } \\
\hline G & Hasil sortiran cabai tidak dimanfaatkan/ dikembalikan ke petani & 0,07 & 2,2 & 0,15 \\
\hline $\mathrm{H}$ & $\begin{array}{l}\text { Sortasi dan grading membutuhkan waktu yang lama terutama saat panen } \\
\text { raya cabai di Kabupaten Sleman }\end{array}$ & 0.09 & 2,6 & 0,23 \\
\hline I & $\begin{array}{l}\text { Terdapat perbedaan manajemen dan sistem antara Pasar Lelang Cabai } \\
\text { Kabupaten Sleman dan titik kumpul cabai di Kabupaten Sleman }\end{array}$ & 0,09 & 2,8 & 0,25 \\
\hline $\mathrm{J}$ & $\begin{array}{l}\text { Peserta lelang hanya melibatkan pedagang dari Daerah Istimewa } \\
\text { Yogyakarta dan Jawa Tengah }\end{array}$ & 0,09 & 2,4 & 0,21 \\
\hline K & $\begin{array}{l}\text { Kegiatan lelang masih menggunakan saluran telepon, sms, whatsapp dan } \\
\text { lainnya }\end{array}$ & 0,1 & 3 & 0,3 \\
\hline \multicolumn{2}{|r|}{ Total } & 1 & - & 3,02 \\
\hline
\end{tabular}

Sumber : Olahan Data Primer, 2020 
P-ISSN: 1858-1226; E-ISSN: 2723-4010

Bulan Juli Tahun 2020, Vol. 27 No. 1

Matriks Faktor Strategi Eksternal (EFAS)

Berikut ini hasil dari tahap input data berupa Matriks Faktor Strategi Eksternal (EFAS): Hasil analisis matriks EFAS di Pasar Lelang Cabai Kabupaten Sleman menunjukkan total skor 3,22. Skor total yang diperoleh berada diatas rata-rata. Total skor rata-rata adalah 2,5 sehingga dapat disimpulkan Pasar Lelang Cabai Kabupaten Sleman merespon secara baik peluang dan ancaman yang ada. Dengan kata lain strategi Pasar Lelang Cabai Kabupaten Sleman secara efektif mampu menarik keuntungan dari peluang yang ada dan meminimalkan pengaruh negatif dari ancaman eksternal.

Tabel 2. Matriks EFAS

\begin{tabular}{|c|c|c|c|c|}
\hline \multicolumn{5}{|c|}{ Faktor Strategi Eksternal } \\
\hline Peluang & & Bobot & Rating & Skor \\
\hline A & $\begin{array}{l}\text { Pedagang memilih membeli cabai di Pasar Lelang karena kualitas } \\
\text { cabai yang dijamin. }\end{array}$ & 0,08 & 3,8 & 0,30 \\
\hline B & $\begin{array}{l}\text { Jaringan pemasaran pedagang ke pasar lokal bahkan merambah ke } \\
\text { luar kota dan keluar pulau jawa. }\end{array}$ & 0,06 & 2,4 & 0,14 \\
\hline $\mathrm{C}$ & $\begin{array}{l}\text { Tengkulak menentukan harga dengan acuan harga yang ada di pasar } \\
\text { lelang sehingga harga cabai dapat dikontrol dan tidak terlalu jatuh }\end{array}$ & 0,06 & 3,2 & 0,19 \\
\hline $\mathrm{D}$ & Petani percaya dengan pengelola lelang dan titik kumpul & 0,07 & 3 & 0,21 \\
\hline $\mathrm{E}$ & $\begin{array}{l}\text { Website penenin.id untuk pasar lelang, dan titik kumpul dari Bank } \\
\text { Indonesia }\end{array}$ & 0,08 & 4 & 0,32 \\
\hline $\mathrm{F}$ & $\begin{array}{l}\text { Adanya dukungan dari Dinas Pertanian Pangan dan Perikanan } \\
\text { Kabupaten Sleman untuk pasar lelang dan titik kumpul }\end{array}$ & 0,07 & 4 & 0,28 \\
\hline G & $\begin{array}{l}\text { Adanya bantuan sarana prasarana dari Dinas Pertanian Pangan dan } \\
\text { Perikanan Kabupaten Sleman kepada petani yang rajin menjual hasil } \\
\text { panennya ke pasar lelang atau titik kumpul }\end{array}$ & 0,07 & 3,4 & 0,24 \\
\hline $\mathrm{H}$ & $\begin{array}{l}\text { Dukungan penyuluh yang mendorong kelompok tani binaannya } \\
\text { untuk menjual hasil panen ke pasar lelang dan penyuluhan tentang } \\
\text { pengembangan teknis budidaya cabai. }\end{array}$ & 0,06 & 3,4 & 0,20 \\
\hline \multicolumn{5}{|c|}{ Ancaman } \\
\hline $\mathrm{I}$ & Pedagang yang membeli cabai di tengkulak & 0,07 & 2,8 & 0,17 \\
\hline $\mathrm{J}$ & $\begin{array}{l}\text { Belum tercapainya pemenuhan kebutuhan cabai di Kabupaten } \\
\text { Sleman oleh pasar lelang }\end{array}$ & 0,06 & 2,4 & 0,14 \\
\hline $\mathrm{K}$ & $\begin{array}{l}\text { Belum ada persyaratan yang spesifik untuk menjadi } \\
\text { pedagang/konsumen di pasar lelang/titik kumpul yang berpotensi } \\
\text { menyebabkan gagal bayar }\end{array}$ & 0,07 & 3 & 0,21 \\
\hline $\mathrm{L}$ & $\begin{array}{l}\text { Adanya tengkulak terutama di wilayah sentra-sentra cabai di } \\
\text { Kabupaten Sleman }\end{array}$ & 0,07 & 3 & 0,21 \\
\hline M & $\begin{array}{l}\text { Serangan hama dan penyakit pada tanaman cabai petani sehingga } \\
\text { tidak lolos sortir }\end{array}$ & 0,06 & 3 & 0,18 \\
\hline $\mathrm{N}$ & $\begin{array}{l}\text { Terdapat petani yang tidak menyortir cabainya sebelum dibawa ke } \\
\text { pasar lelang }\end{array}$ & 0,05 & 3,2 & 0,16 \\
\hline $\mathrm{O}$ & $\begin{array}{l}\text { Proses budidaya cabai belum sesuai sehingga perlu ditingkatkan lagi } \\
\text { baik dari analisis usaha, pelaksanaan budidaya maupun pemanfaatan } \\
\text { teknologi }\end{array}$ & 0,07 & 3,8 & 0,27 \\
\hline Total & & 1 & - & 3,22 \\
\hline
\end{tabular}

Sumber :Olahan Data Primer, 2020 
P-ISSN: 1858-1226; E-ISSN: 2723-4010

Bulan Juli Tahun 2020, Vol. 27 No. 1

\begin{tabular}{lcccc}
\hline & & \multicolumn{3}{c}{ Total Nilai IFAS } \\
\cline { 3 - 5 } & & Tinggi & Sedang & Rendah \\
Tinggi & $3,00-4,00$ & $2,00-2,99$ & $1,00-1,99$ \\
& $3,00-4,00$ & I & II & III \\
Sedang & IV & V & VI \\
Total Nilai EFAS & $2,00-2,99$ & & & IX \\
& Rendah & VII & VIII & I,00-1,99 \\
& & &
\end{tabular}

Gambar 1. Analisis Matriks Internal-Eksternal Pasar Lelang Cabai Kabupaten Sleman

\section{Tahap Pencocokan}

\section{Matriks IE}

Berdasarkan analisis matriks IFAS dan EFAS didapatkan jumlah skor pada masing-masing matriks. Pada matriks IFAS total skor adalah 3,02 sedangkan pada matriks EFAS total skor adalah 3,22.

Dari gambar 1 diatas dapat disimpulkan bahwa pengembangan Pasar Lelang Cabai
Kabupaten Sleman berada pada sel I yaitu tumbuh dan membangun (grow and build). Pada keadaan ini perusahaan dapat menerapkan strategi intensif yaitu penetrasi pasar, pengembangan pasar, dan pengembangan produk (David,2009).

\section{Matriks SWOT}

Matriks SWOT Pasar Lelang Cabai Kabupaten Sleman adalah sebagai berikut:

Tabel 3. Keterkaitan Strategi Pada Matriks IE dengan Matriks SWOT

Pada Pengembangan Pasar Lelang Cabai Kabupaten Sleman

\begin{tabular}{|c|c|c|}
\hline No & Strategi Matriks SWOT & Strategi Matriks IE \\
\hline \multicolumn{3}{|c|}{ Strategi SO } \\
\hline 1 & $\begin{array}{l}\text { Mempertahankan dan meningkatkan kualitas dan kuantitas cabai di pasar } \\
\text { lelang untuk menjamin kepuasan pedagang dengan memanfaatkan } \\
\text { teknologi dan dukungan dari Dinas Pertanian Pangan dan Perikanan } \\
\text { Kabupaten Sleman. }\end{array}$ & Pengembangan produk \\
\hline 2 & $\begin{array}{l}\text { Perluasan pemasaran hingga tingkat nasional dengan memanfaatkan } \\
\text { website panenin.id untuk mengadakan kegiatan lelang }\end{array}$ & Pengembangan pasar \\
\hline \multicolumn{3}{|c|}{ Strategi WO } \\
\hline 3 & $\begin{array}{l}\text { Pembenahan sistem dan manajemen di titik kumpul agar dapat } \\
\text { menyesuaikan dengan sistem dan manajemen yang sudah ada di pasar } \\
\text { lelang. }\end{array}$ & $\begin{array}{l}\text { Pengembangan produk dan } \\
\text { pengembangan pasar }\end{array}$ \\
\hline 4 & $\begin{array}{l}\text { Cabai setoran petani diambil semua dengan mencari pasar yang } \\
\text { menerima cabai yang tidak lolos sortir namun masih layak konsumsi. }\end{array}$ & Pengembangan pasar \\
\hline 5 & Mengoptimalkan kegiatan penyuluhan dan memanfaatkan bantuan & Pengembangan produk \\
\hline \multicolumn{3}{|c|}{ Strategi ST } \\
\hline 6 & $\begin{array}{l}\text { Pendataan kebutuhan pasar lokal di wilayah Kabupaten Sleman baik dari } \\
\text { pasar lelang maupun titik kumpul. }\end{array}$ & Penetrasi pasar \\
\hline 7 & $\begin{array}{l}\text { Membuat ketentuan persyaratan untuk dapat menjadi } \\
\text { pedagang/konsumen di pasar lelang maupun titik kumpul. } \\
\text { Strategi WT }\end{array}$ & Pengembangan pasar \\
\hline 8 & $\begin{array}{l}\text { Meningkatkan kualitas hasil panen cabai petani dengan peningkatan } \\
\text { keterampilan dalam teknologi budidaya cabai untuk menghindari } \\
\text { serangan hama dan meningkatkan produksi serta memenuhi kebutuhan } \\
\text { pasar. }\end{array}$ & Pengembangan produk \\
\hline 9 & $\begin{array}{l}\text { Sosialisasi lebih intensif kepada petani tentang pentingnya cabai disortir } \\
\text { sebelum dibawa ke pasar lelang dan penyampaian kriteria cabai yang } \\
\text { baik. }\end{array}$ & Pengembangan produk \\
\hline
\end{tabular}

Sumber :Olahan Data Primer, 2020 
Tahap Pengambilan Keputusan QSPM (Quantitative Strategic Matrix)

Setelah dilakukan input data pada tahap analisis yaitu matriks IFAS dan EFAS serta pencocokan dengan matriks IE dan SWOT selanjutnya tahap keputusan dengan QSPM (Quantitative Strategic Matrix). QSPM berisi faktor kekuatan, kelemahan, peluang dan ancaman serta bobot dari masing masing faktor tersebut kemudian diberi masing-masing nilai
Attractives Score (AS) atau nilai daya tarik dari masing-masing faktor terhadap strategi. Nilai $A S$ dikali dengan bobot dari masing-masing faktor kemudian didapat nilai Total Attractiveness Score (TAS). Kemudian seluruh nilai TAS dari masingmasing faktor tersebut dijumlahkan sehingga diperoleh nilai Sum Total Attractiveness Score (STAS). Hasil analisis data $Q S P M$ sebagai berikut.

Tabel 4. Hasil Analisis Data QSPM

\begin{tabular}{lcc}
\hline \multicolumn{1}{c}{ Alternatif Strategi } & STAS & Peringkat \\
\hline Strategi I & 7,13 & 1 \\
Strategi II & 6,83 & 2 \\
Strategi III & 5,34 & 5 \\
Strategi IV & 5,01 & 6 \\
Strategi V & 5,01 & 6 \\
Strategi VI & 4,13 & 8 \\
Strategi VII & 4,38 & 7 \\
Strategi VIII & 5,84 & 3 \\
Strategi XI & 5,69 & 4 \\
\hline
\end{tabular}

Sumber : Olahan Data Primer, 2020

Selengkapnya strategi berdasarkan peringkat STAS antara lain :

1. Mempertahankan dan meningkatkan kualitas dan kuantitas cabai di pasar lelang untuk menjamin kepuasan pedagang dengan memanfaatkan teknologi dan dukungan dari Dinas Pertanian Pangan dan Perikanan Kabupaten Sleman $(7,13)$

2. Perluasan pemasaran hingga tingkat nasional dengan memanfaatkan website panenin.id untuk mengadakan kegiatan lelang $(6,83)$

3. Meningkatkan kualitas hasil panen cabai petani dengan peningkatan keterampilan dalam teknologi budidaya cabai untuk menghindari serangan hama dan meningkatkan produksi serta memenuhi kebutuhan pasar $(5,84)$

4. Sosialisasi lebih intensif kepada petani tentang pentingnya cabai disortir sebelum dibawa ke pasar lelang dan penyampaian kriteria cabai yang baik $(5,69)$
5. Pembenahan sistem dan manajemen di titik kumpul agar dapat menyesuaikan dengan sistem dan manajemen yang sudah ad di pasar lelang $(5,34)$

6. Cabai setoran petani diambil semua dengan mencari pasar yang menerima cabai yang tidak lolos sortir namun masih layak konsumsi dan mengoptimalkan kegiatan penyuluhan dan memanfaatkan bantuan sarana prasarana untuk menunjang kegiatan budidaya cabai yang lebih baik $(5,01)$

7. Membuat ketentuan persyaratan untuk dapat menjadi pedagang/konsumen di pasar lelang maupun titik kumpul $(4,38)$

8. Pendataan kebutuhan pasar lokal di wilayah Kabupaten Sleman baik dari pasar lelang maupun titik kumpul $(4,13)$

\section{SIMPULAN DAN SARAN}

Analisis lingkungan internal menunjukan bahwa Pasar Lelang Cabai Kabupaten Sleman memiliki kekuatan utama berupa memiliki website panenin.id yang dapat digunakan sebagai pencatatan 
dan fungsi lainnya. Sedangkan untuk kelemahan utama yang dimiliki oleh Pasar Lelang Cabai Kabupaten Sleman adalah cabai yang tidak lolos sortir dikembalikan kepada petani. Analisis lingkungan eksternal menunjukan bahwa Pasar Lelang Cabai Kabupaten Sleman memiliki peluang utama berupa dukungan dari Bank Indonesia salah satu wujudnya adalah website panenin.id yang dapat digunakan oleh pasar lelang maupun titik kumpul. Namun terdapat pula ancaman bagi Pasar Lelang Cabai Kabupaten Sleman diantaranya adanya belum tercapainya kebutuhan lokal cabai di Kabupaten Sleman.

Hasil kajian menunjukan bahwa terdapat prioritas strategi dan strategi alternatif lainnya yang dapat diterapkan oleh Pasar Lelang Cabai Kabupaten Sleman. Prioritas strategi tersebut adalah mempertahankan dan meningkatkan kualitas dan kuantitas cabai di pasar lelang untuk menjamin kepuasan pedagang dengan memanfaatkan teknologi dan dukungan dari Dinas Pertanian Pangan dan Perikanan Kabupaten Sleman.

\section{PUSTAKA ACUAN}

Badan Pengawas Perdagangan Berjangka Komoditi. (2017). Pasar Lelang Komoditas Memperpendek Mata Rantai Perdagangan. Jakarta.

Badan Pusat Statistik Sleman. (2019). Kabupaten Sleman dalam Angka 2019. Sleman

Badan Pusat Statistik. (2019). Pola Distribusi Perdagangan Komoditas Strategis. Jakarta

David, Fred R. (2009). Konsep Manajemen Strategis (Edisi 12). Jakarta: Salemba Empat.

David, Fred R. (2016). Manajemen Strategik Suatu Pendekatan Keunggulan Bersaing (Edisi 15). Jakarta: Salemba Empat.
Dinas Pertanian Pangan dan Perikanan Kabupaten Sleman. (2018). Data Cabai Kabupaten Sleman. Sleman

Dinas Pertanian Pangan dan Perikanan Kabupaten Sleman. (2018). Data Statistik Hortikultura Tahun 2018. Sleman

Dinas Pertanian Pangan dan Perikanan Kabupaten Sleman. (2019). Programa Penyuluhan Pertanian, Pangan dan Perikanan Kehutanan Sleman Tahun 2019. Sleman

Pemerintah Kabupaten Sleman. (2020). Letak dan Luas Wilayah. http://www.slemankab.go.id/profilkabupaten-sleman/geografi/letakdan-luas-wilayah. Diakses 01 April 2020.

Pemerintah Daerah Istimewa Yogyakarta. (2019). Laporan Keterangan Pertanggungjawaban Gubernur Daerah Istimewa Yogyakarta. Yogyakarta

Rangkuti, Freddy. (2016). Analisis SWOT : Teknik Membedah Kasus Bisnis Cara Perhitungan Bobot, Rating, dan OCAI. Jakarta: Gramedia Pustaka Utama.

Sugiyono. (2019). Metode Penelitian Kuantitatif Kualitatif dan R\&D. Bandung: Alfabeta.

Suryowati, E. (2016). BPS : Rantai Distribusi Cabai Merah Paling Panjang.

https://money.kompas.com/read/201 6/02/01/133639726/BPS.Rantai.Dist ribusi.Cabai.Merah.Paling.Panjang. Diakses pada 21 Desember 2019.

Suyanto., B, Sutinah. (2015). Metode Penelitian Sosial Berbagai Alternatif Pendekatan. Jakarta: Prenadamedia Group.

Swastika., S, Pratama., D, Hidayat., T, Andri., K, B. (2017). Buku Petunjuk Teknis Teknologi Budidaya Cabai Merah. Riau: UR Press 